\title{
Sacubitril/valsartan and the risk of sudden cardiac death
}

\author{
Krzysztof Ozierański ${ }^{1 \mathrm{~A}-\mathrm{F}}$, Paweł Balsam ${ }^{1 \mathrm{~A}-\mathrm{F}}$, Jędrzej Kosiuk ${ }^{2,3, A-F}$, Marcin Grabowski ${ }^{1, \mathrm{~A}-\mathrm{F}}$ \\ A - Research concept and design, B - Collection and/or assembly of data, C - Data analysis and interpretation, \\ D - Writing the article, E - Critical revision of the article, F - Final approval of article \\ 1. $1^{\text {st }}$ Department of Cardiology Medical University of Warsaw \\ 2. Department of Electrophysiology, Helios Clinic Koethe \\ 3. Medical Faculty of University of Leipzig
}

\begin{abstract}
Address for correspondence:
Krzysztof Ozieranski, $1^{\text {st }}$ Department of Cardiology, Medical University of Warsaw email: krzysztof.ozieranski@gmail.com
\end{abstract}

Paweł Balsam, $1^{\text {st }}$ Department of Cardiology, Medical University of Warsaw

email: pawel.balsam@me.com

Jędrzej Kosiuk, Department of Electrophysiology, Helios Clinic Koethen, Medical Faculty of University of Leipzig email: jedrzejkosiuk@hotmail.com

Marcin Grabowski, $1^{\text {st }}$ Department of Cardiology, Medical University of Warsaw email: grabowski.marcin@me.com

Received: 2018-10-14

Revised:

Accepted: 2018-10-18

Final review: 2018-10-14

DOI: $10.24255 / \mathrm{hbj} / 99045$

\section{Key words:}

\section{Abstract}

Patients with heart failure (HF) with reduced left ventricle ejection fraction (HFrEF) are at high risk of sudden cardiac death (SCD). Therefore HFrEF treatment requires further improvement, which may be accomplished with the use of sacubitril/valsartan. Sacubitril/valsartan reduce the risks of allcause mortality, cardiovascular mortality, SCD, HF mortality, $\mathrm{HF}$ and all-cause hospitalizations, as well as symptoms of HF. It was also shown that use of sacubitril/valsartan may be associated with a reduced number of adequate and inadequate

Current trends show that the prevalence of heart failure $(\mathrm{HF})$ is still increasing ${ }^{(1)}$. Patients with HF with reduced left ventricle ejection fraction (HFrEF) are at high risk of sudden cardiac death $(\mathrm{SCD})^{(2)}$. In the PARADIGM-HF (Prospective Comparison of Angiotensin Receptor-Neprilysin Inhibitor With an Angiotensin-Converting Enzyme Inhibitor to Determine Impact on Global Mortality and Morbidity in Heart Failure) trial approximately $40 \%$ of deaths of HFrEF patients were related to SCD caused mainly by ventricular arrhythmia ${ }^{(3)}$. The risk of SCD in HFrEF may be reduced with guideline-rec- device interventions in HFrEF patients with an implantable cardioverter defibrillator, and an increased percentage of biventricular pacing in patients with cardiac resynchronization therapy. Sacubitril/valsartan blocks the angiotensin II receptor (valsartan) and inhibits neprilysin (sacubitril) simultaneously. It results in inhibited sympathetic activity, as well as decreased cardiac remodeling and fibrosis, resulting in a decreased pro-arrhythmogenic effect.

ommended treatment with angiotensin converting enzyme inhibitors (ACE-I), beta-blockers, mineralocorticoid receptor antagonists (MRA), as well as with device therapies such as implantable cardioverter defibrillator (ICD) and cardiac resynchronization therapy (CRT). Angiotensin-receptor blockers (ARB) should be restricted to patients unable to tolerate ACE-I or potentially used in addition to ACE-I instead of MRA in the case of intolerance ${ }^{(2)}$.

The PARADIGM-HF (Prospective Comparison of Angiotensin Receptor-Neprilysin Inhibitor With an Angiotensin-Con- 
verting Enzyme Inhibitor to Determine Impact on Global Mortality and Morbidity in Heart Failure) study was terminated ahead of time (after a median of 27 months of observation) because of observed clear benefits of sacubitril/valsartan compared to enalapril. Sacubitril/valsartan significantly reduced the risks of all-cause mortality, cardiovascular mortality, $\mathrm{SCD}, \mathrm{HF}$ mortality, HF and all-cause hospitalizations, as well as symptoms of $\mathrm{HF}^{(3)}$. It is important that the advantages of treatment with sacubitril/valsartan persist even after the need for dose reduction and are similar to those observed in patients without any dose reduction ${ }^{(4)}$.

It was also shown that use of sacubitril/valsartan was also associated with a reduced number of adequate and inadequate device interventions in HFrEF patients with an implanted ICD. Sacubitril/valsartan reduced the risk of sustained and nonsustained ventricular tachycardia, as well as the risk of premature ventricular contractions, which translated into a higher rate of biventricular pacing in patients with CRT. In addition, a trend was observed to reduce the incidence of paroxysmal atrial tachycardia and atrial fibrillation ${ }^{(5)}$. In the PARADIGM-HF study patients treated with sacubitril/valsartan were less likely to require implantation of a cardiac device or cardiac transplantation ${ }^{(3)}$.

Sacubitril/valsartan blocks the angiotensin II receptor (valsartan) and inhibits neprilysin (sacubitril) simultaneously. Inhibition of the AT2 receptor results in decreased sympathetic activity and inhibits cardiac hypertrophy, reverse remodeling and fibrosis, and therefore inhibits the pro-arrhythmogenic effect. Neprilysin is an enzyme that degrades natriuretic and vasoactive peptides and is overstimulated in patients with HF. Neprilysin inhibition, by sacubitril, causes beneficial effects on the cardiovascular system through the vasodilating effect and increasing the availability of natriuretic peptides, which in turn leads to growth of natriuresis and diuresis, as well as reduction of left ventricular and vascular remodeling ${ }^{(6,7)}$.

The reduction of the risk of ventricular arrhythmia in the PARADIGM trial might have resulted from intensification of HF treatment through connection of these two molecules sacubitril and valsartan. Reduction of preload and afterload, improvement of the left ventricular function obtained by neprilysin inhibition, as well as reduction of myocardial fibrosis, myocardial ischemia and sympathetic tone by valsartan, might play an important role in modification of the substrate for fatal ventricular arrhythmias.

Mortality benefits of sacubitril/valsartan use are particularly related to modification of the risk for SCD and death due to HF worsening, giving a real chance for further improvement in HF therapy.

\section{References}

1. Yancy CW, Januzzi JL, Jr., Allen LA, Butler J, Davis LL, Fonarow GC, et al. 2017 ACC Expert Consensus Decision Pathway for Optimization of Heart Failure Treatment: answers to 10 pivotal issues about heart failure with reduced ejection fraction: a report of the American College of Cardiology Task Force on Expert Consensus Decision Pathways. J Am Coll Cardiol. 2018;71(2):201-30.

2. Ponikowski P, Voors AA, Anker SD, Bueno H, Cleland JG, Coats AJ, et al. [2016 ESC Guidelines for the diagnosis and treatment of acute and chronic heart failure]. Kardiol Pol. 2016;74(10):1037-147.

3. McMurray JJ, Packer M, Desai AS, Gong J, Lefkowitz MP, Rizkala AR, et al. Angiotensin-neprilysin inhibition versus enalapril in heart failure. N Engl J Med. 2014;371(11):993-1004.

4. Vardeny O, Claggett B, Packer M, Zile MR, Rouleau J, Swedberg K, et al. Efficacy of sacubitril/valsartan vs. enalapril at lower than target doses in heart failure with reduced ejection fraction: the PARADIGM-HF trial. Eur J Heart Fail. 2016;18(10):1228-34.

5. de Diego C, Gonzalez-Torres L, Nunez JM, Centurion Inda $\mathrm{R}$, Martin-Langerwerf DA, Sangio AD, et al. Effects of angiotensin-neprilysin inhibition compared to angiotensin inhibition on ventricular arrhythmias in reduced ejection fraction patients under continuous remote monitoring of implantable defibrillator devices. Heart Rhythm. 2018;15(3):395-402.

6. Nessler J, Straburzynska-Migaj E, Windak A, Solnica B, Szmitkowski M, Paradowski M, et al. [Expert consensus on the usefulness of natriuretic peptides in heart failure.]. Kardiol Pol. 2018;76(1):215-24.

7. Mills J, Vardeny O. The role of neprilysin inhibitors in cardiovascular disease. Curr Heart Fail Rep. 2015;12(6):389-94. 